\title{
Hepatic lesions in patients treated with synthetic anabolic steroids
}

\author{
E. C. SWEENEY AND D. J. EVANS \\ From the Department of Histopathology, Royal Postgraduate Medical School, Du Cane Road, \\ London W12 OHS
}

SYNOPSIS Hepatic abnormalities are described in three patients who received synthetic anabolic 용 steroids. A child with Fanconi's anaemia was treated for four years and at necropsy the liver showed No generalized hyperplasia, hyperplastic nodules, and a benign hepatoma. Two adults received only three months' therapy with synthetic androgens; in one there was generalized hepatic hyperplasia and in the other widespread nodular hyperplasia. It is suggested that anabolic steroids may induce tumours through intermediate hyperplastic lesions, a sequence similar to that seen during tumour induction by carcinogens in experimental animals.

Although it appears clear on the basis of a number of case reports that liver tumours in man are significantly associated with the administration of synthetic anabolic steroids, the mechanisms involved have not yet been elucidated. In the majority of these case reports there is no description of the liver parenchyma but occasionally the tumours have been said to arise in a normal liver or in one which shows cirrhosis or peliosis hepatis.

\section{Case reports}

CASE 1

A 5-year-old boy presented for investigation of pancytopenia. His height was less than the third percentile and his weight was in the tenth percentile. Both thumbs were absent and there was microcephaly and microphthalmia. The skin exhibited café-au-lait patches and both testes were undescended. The haemoglobin was $10.3 \mathrm{~g} / \mathrm{dl}$, reticulocytes $4 \%$, and white cell count $3.3 \times 10^{9} / 1$. The bone marrow was mildly hypoplastic with marked suppression of thrombopoiesis. Chromosomal analysis revealed a $46 \mathrm{XY}$ karyotype and $25 \%$ of the cells exhibited chromosome breaks. A radiographic skeletal survey showed absent thumbs and a bone age of approximately 2 years 8 months. Liver function tests and an intravenous pyelogram were normal. A diagnosis of Fanconi's anaemia was made (a younger brother was similarly affected) and the patient was started on prednisolone, $15 \mathrm{mg}$, and

Received for publication 18 December 1975 methyl testosterone, $20 \mathrm{mg}$ daily. Over the next three years blood counts remained satisfactory but marked virilization and bouts of jaundice necessitated replacement of testosterone by a reduced dose of oxymetholone. At the end of this period the child was admitted for investigation of a four-week $\frac{\circ}{\Phi}$ episode of jaundice. Therapy at this time was oxy- $\varrho$ metholone, $5 \mathrm{mg}$ daily, and prednisolone, $5 \mathrm{mg}$ on $\overrightarrow{\overrightarrow{0}}$ alternate days. The liver was palpable two fingerbreadths below the costal margin. Investigations showed a haemoglobin of $7.9 \mathrm{~g} / \mathrm{dl}$, abnormal liver function tests including a bilirubin of $43 \mu \mathrm{mol} / 1$ 융 $(2.5 \mathrm{mg} / \mathrm{dl})$, LDH $190 \mathrm{U} / \mathrm{l}$, alkaline phosphatase $230 \mathrm{U} / 1$, and an SGOT of $47 \mathrm{U} / 1$. Serum triglycerides were $2.7 \mathrm{mmol} / 1(239 \mathrm{mg} / \mathrm{dl})$ and cholesterol $16.3 \dot{\delta}$ $\mathrm{mmol} / 1 \mathrm{l}(630 \mathrm{mg} / \mathrm{dl})$. A diagnosis of cholestatic jaundice with hyperlipidaemia due to oxymetholone 0 was made and nandrolone decanoate, $25 \mathrm{mg}$ intramuscularly weekly, was substituted. The jaundice, however, persisted and the haemoglobin level fell so that transfusions were required for the first time. $\%$ Approximately one year later the patient was 0 readmitted for management of melaena following స్ aspirin ingestion. The haemoglobin was now $4 \mathrm{~g} / \mathrm{dl} O$ and the platelets $50 \times 10^{9} / 1$. Serum bilirubin was $60 \mu \mathrm{mol} / 1(3.5 \mathrm{mg} / \mathrm{dl})$, alkaline phosphatase $535 \mathrm{U} / 1$, and SGOT $91 \mathrm{U} / 1$. Alphafetoprotein was negative. $\stackrel{\mathcal{\Phi}}{\sim}$ A liver scan revealed a filling defect with technetium99 which was not apparent with selenomethionine, and selective angiography showed abnormal cir- $\overrightarrow{\mathbb{D}}$ culation in the right lobe of the liver. The patient $\frac{\mathbb{D}}{\mathbb{D}}$ was transfused and discharged on no therapy. Three months later he was readmitted with gastro- 
intestinal bleeding and skin purpura. He became drowsy and confused and died seven days later.

\section{Necropsy findings}

The stomach contained $500 \mathrm{ml}$ of altered blood, and small mucosal haemorrhages and scattered erosions were present. Mucosal erosions were also present in mouth, ileum, and rectum. The heart was slightly enlarged, weighing $152 \mathrm{~g}(\mathrm{~N}=123 \mathrm{~g})$ with left ventricular hypertrophy. Small isolated plaques of atheroma were present in the abdominal aorta. The bone marrow appeared pale. The liver weighed $1350 \mathrm{~g}$ and contained a $9 \mathrm{~cm}$ diameter spherical tumour mass in the upper part of the right lobe. The mass was stained dark green, was distinctly demarcated from the rest of the liver, and was composed of multiple nodules measuring up to $2 \mathrm{~cm}$ in diameter (fig 1). Elsewhere the parenchyma was firm and light-brown in colour, showing no evidence of cirrhosis, but containing innumerable pale, slightly irregular, well-defined nodules (fig 2). These varied in size from $5 \mathrm{~mm}$ down to less than $1 \mathrm{~mm}$. They were of similar consistency to the intervening liver. The portal system and biliary tract were normal and the remainder of the necropsy was unremarkable.

\section{Histology}

Microscopy of the liver tumour showed it to be composed of nodules of uniform cells arranged in interwoven trabeculae and acini or tubules (fig 3). Numerous bile plugs were present, particularly in the centre of the tubular structures. No bile ducts were identified in the multiple sections of the tumour examined. Mitotic figures, although present, were infrequent. In contrast to the rest of the hepatic parenchyma the hepatocytes forming the tumour did not contain iron. The constituent nodules of the tumour mass were separated from each other and the surrounding liver by dense fibrous trabeculae. Restricted to an area adjacent to the tumour there was portal fibrosis with occasional zones of bile-duct reduplication (fig 4). Elsewhere there was generalized hyperplasia of the hepatic parenchyma, evidenced by increased mitotic activity and inordinate numbers of thickened liver cell plates (fig 5). Hyperplastic hepatocytic nodules without surrounding fibrosis were scattered throughout the liver (fig 6). These nodules, in common with the main tumour mass, failed to show the heavy iron deposition in their constituent hepatocytes which was a feature of most of the liver parenchyma. In conclusion it was felt that the tumour in the right lobe of the liver was a benign hepatoma and that the rest of the liver demonstrated generalized hyperplasia with nodule formation. The testis was prepubertal and contained much iron, and the lung demonstrated numerous haemosiderin-laden macrophages in the septa and alveoli.

\section{CASE 2}

A 46-year-old man developed a persistent chest infection and was referred to another hospital for investigation. The haemoglobin was $9.9 \mathrm{~g} / \mathrm{dl}$, white cell count $1 \cdot 1 \times 10^{9} / 1$ with $50 \%$ neutrophils, and platelets $35 \times 10^{9} / 1$. Bone marrow aspirate revealed hypoplasia of all elements. A diagnosis of aplastic anaemia was made and treatment with oxymetholone, $100 \mathrm{mg}$ daily, and prednisone was started. Over the next three months there was little improvement in the haematological status in spite of doses of oxymetholone up to $300 \mathrm{mg}$ daily. Pyrexia developed, which was treated empirically with antibiotics, and the patient was transferred to the Hammersmith Hospital. On admission he was taking $150 \mathrm{mg}$ oxymetholone and $5 \mathrm{mg}$ prednisone daily. Examination revealed marked jaundice and purpuric spots in the mouth and over the arms and back. The haemoglobin was $8.5 \mathrm{~g} / \mathrm{dl}$, platelets $11 \times 10^{9} / 1$, and white cell count $0.6 \times 10^{9} / 1$. The bilirubin was $168 \mu \mathrm{mol} / 1$ $(9.8 \mathrm{mg} / \mathrm{dl})$, alkaline phosphatase $1510 \mathrm{U} / \mathrm{l}$, and SGOT $102 \mathrm{U} / \mathrm{l}$. Renal function declined and necessitated the institution of peritoneal dialysis. Terminally there was infection and collapse of the lower lobe of the right lung, liver failure, and uraemic pericarditis.

\section{Necropsy findings}

There was a fibrinous pericarditis and bronchopneumonia in the lower lobe of the right lung with abscess formation. Both kidneys were enlarged but appeared normal macroscopically. The bone marrow was pale. The liver was enlarged and firm and

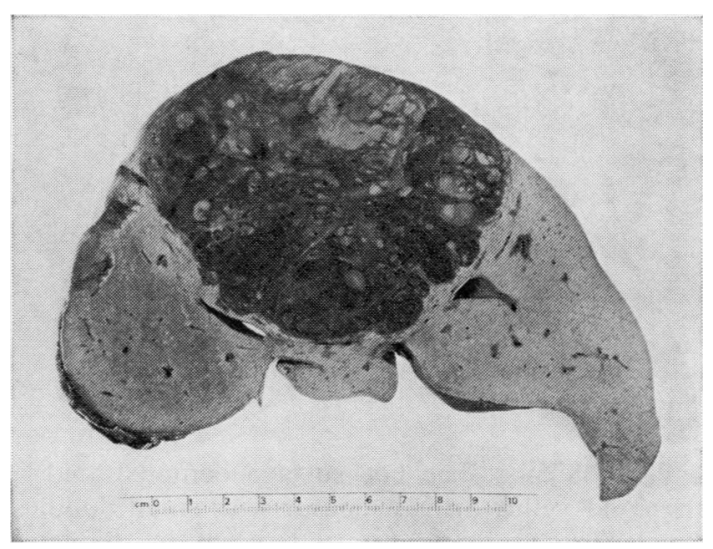

Fig 1 Case 1. Coronal slice of liver showing the circumscribed tumour in the right lobe. 


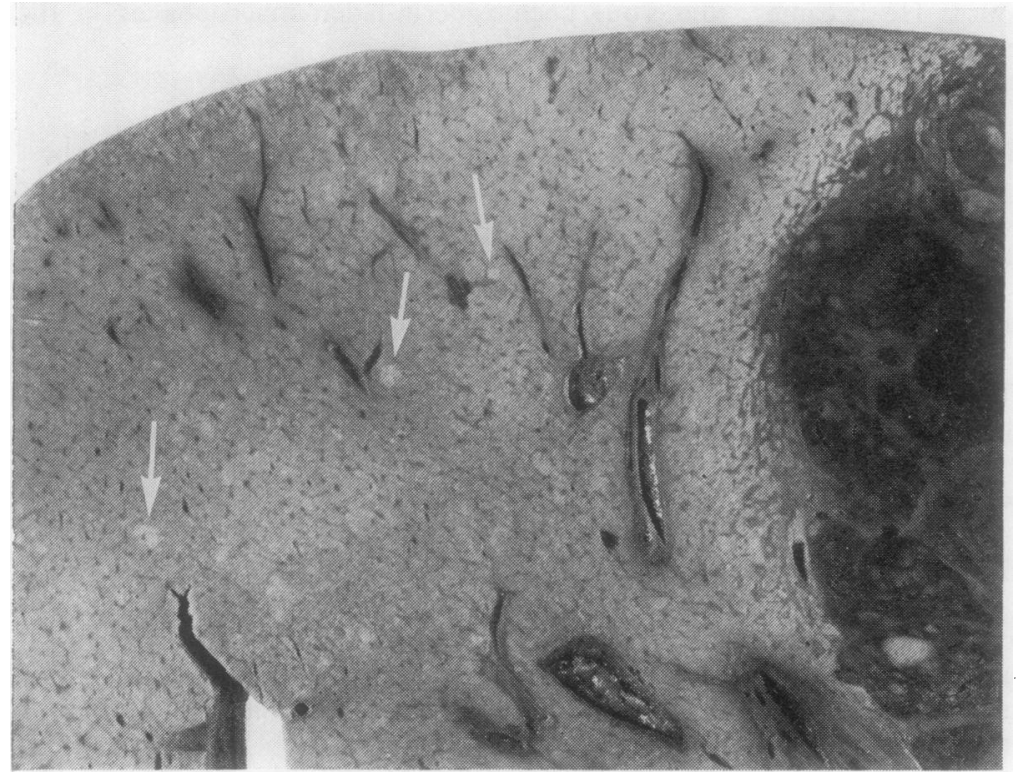

Fig 2 Case 1. Close-up view of liver illustrating the pale hyperplastic parenchymal nodules (arrowed) at a distance from the tumour.

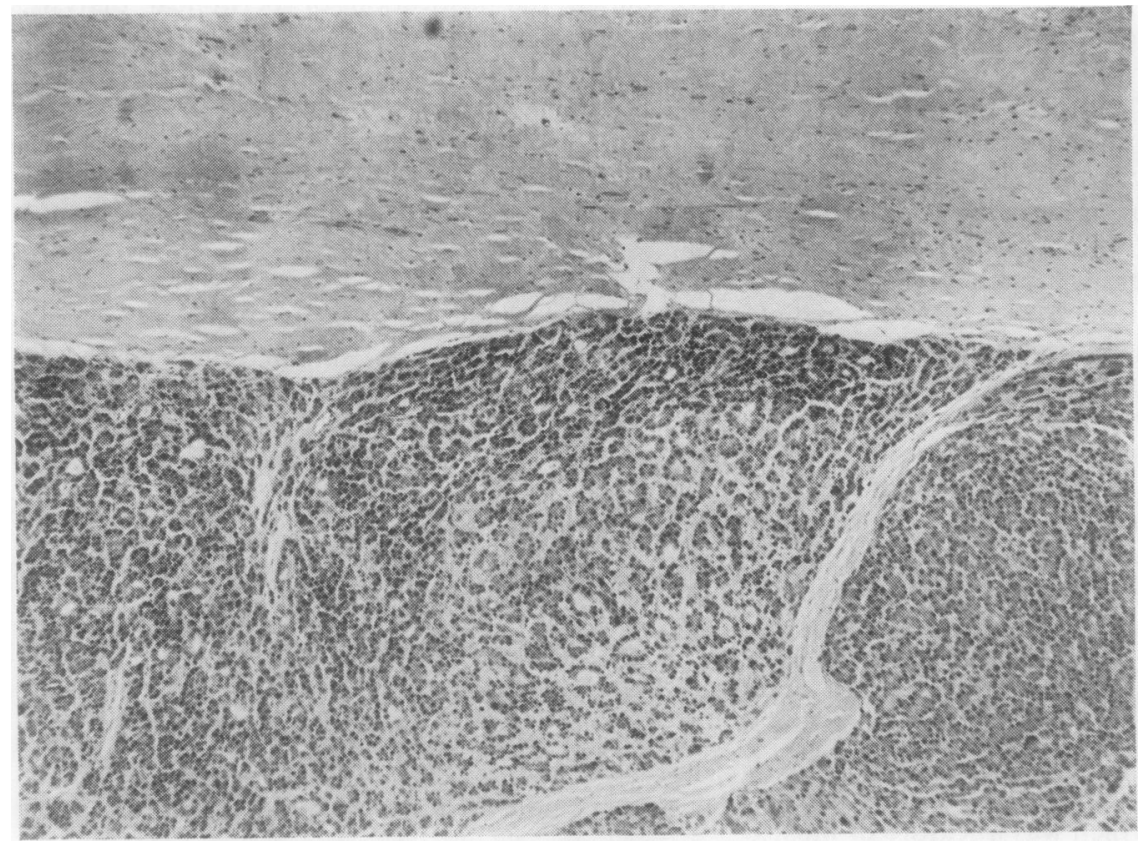

Fig 3 Case 1. Lowpower view of edge of tumour showing acinar $\overrightarrow{\vec{B}}$ arrangement of tumour 3 cells and dense fibrous capsule. Haematoxylin and eosin $\times 45$.

weighed $1875 \mathrm{~g}$. The cut surface demonstrated a variegated yellow-brown colour with small nodules of pale brown tissue up to $0.5 \mathrm{~cm}$ in diameter scattered throughout the parenchyma. The portal system and biliary tract were normal.
Histology

Microscopy of the liver revealed circumscribe $\vec{\Phi}$ hyperplastic nodules of hepatocytes composed of cell-plates two or more cells thick (fig 7). These nodules were generally situated in the midzones of 


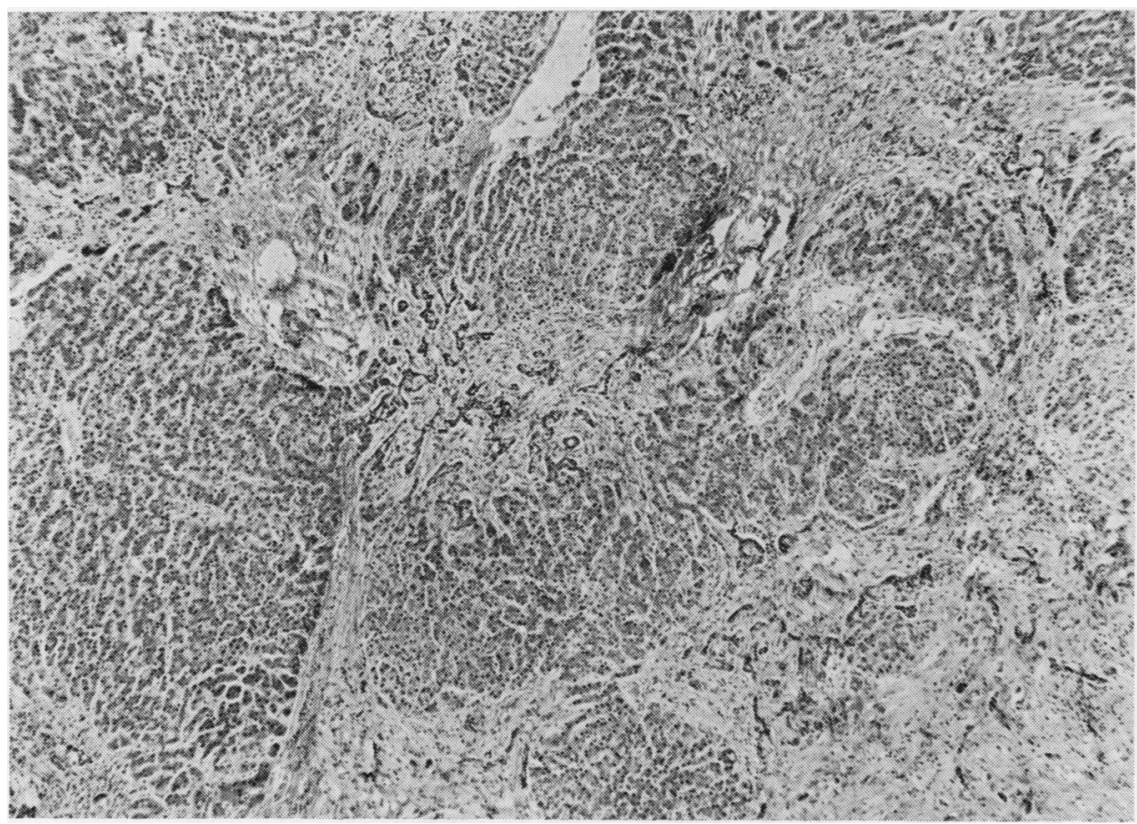

Fig 4 Case 1. Lowpower view of hepatic parenchyma immediately outside the tumour capsule. The fibrosis, bile duct reduplication, and nodular hyperplasia closely mimic cirrhosis. $H$ and $E \times 37$.

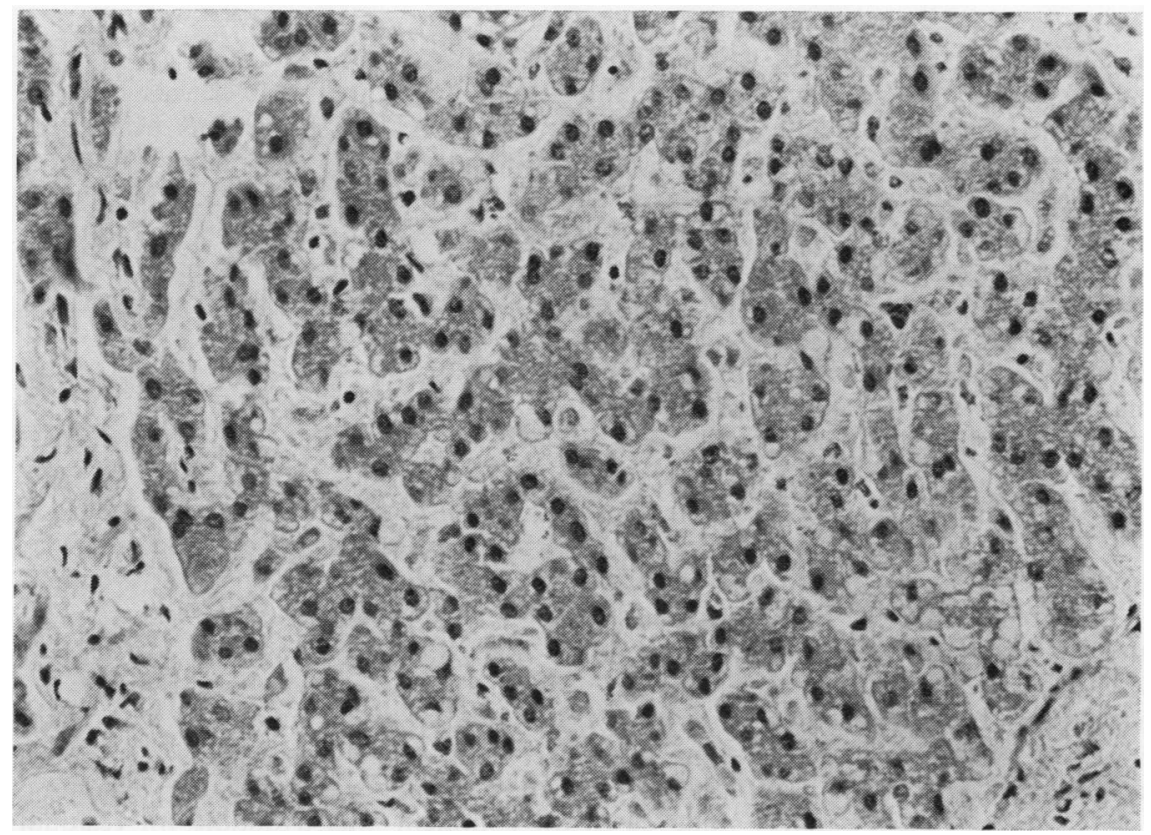

Fig 5 Case 1. Highpower view of hepatic parenchyma taken at random away from the tumour and any visible nodules. All the liver cell plates are thickened and hyperplastic. $H$ and $E$ $\times 375$.

lobules. There was no distortion of the hepatic architecture and no evidence of cirrhosis. Widespread cholestasis was evident and there was minor accumulation of iron in the Kuppfer cells.
CASE 3

A 31-year-old woman was investigated for longstanding dysmenorrhoea and was found to have pancytopenia. Investigations at that time revealed 


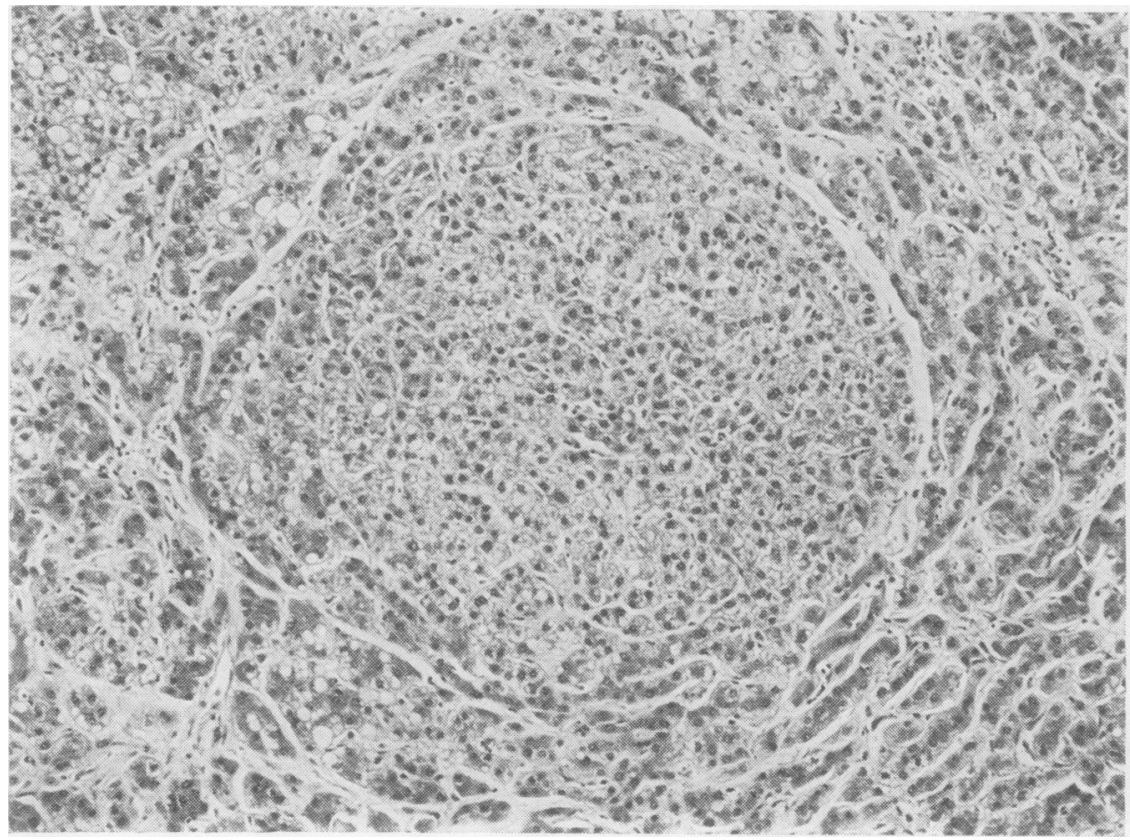

Fig 6 Case 1. A hyperplastic nodule situated at a distance from the tumour. Note the lack of surrounding fibrosis and the compressed hyperplastic liver cell plates arranged circumferentially around the nodule. $H$ and $E \times 112$.

aplastic anaemia and the patient was treated with prednisone and oxymetholone, $50 \mathrm{mg}$ daily. Three months later vaginal bleeding developed and she was admitted to the Hammersmith Hospital. On admission the haemoglobin was $4.5 \mathrm{~g} / \mathrm{dl}$, white cell count $1.2 \times 10^{9} / 1$, and platelets $10 \times 10^{9} / 1$. Petechiae were present over the trunk and limbs but physical examination was otherwise normal. Fresh blood and platelet transfusions were given but haemorrhagic episodes became frequent with epistaxis, bleeding from the gums, and haematuria. Terminally vaginal bleeding and melaena developed followed by signs of intracerebral haemorrhage.

\section{Necropsy findings}

There was a small $(180 \mathrm{ml})$ pericardial effusion. Petechiae were present on all serosal surfaces. Both lungs were oedematous and haemorrhagic. Multiple haemorrhagic erosions were present throughout the entire gastrointestinal tract and the large bowel was filled with melaena stool. The peritoneal cavity contained $300 \mathrm{ml}$ of bloodstained fluid. The liver was uniformly enlarged and weighed $2020 \mathrm{~g}$. The capsular surface was smooth and the cut surface was firm and of a uniform tan colour. The portal venous system and the biliary tract were normal. There was massive haemorrhage into the right cerebral hemisphere with extensive parenchymal destruction. The bone marrow was pale.

\section{Histology}

The architectural pattern in the liver was normal. Thickening of the liver cell plates was evident in every lobule although this was not uniform throughout the lobules (fig 8). There were frequent mitotic figures, in some areas up to three per high-power field (fig 9). Very small amounts of haemosiderin were present in the Kuppfer cells. There was noevidence of cholestasis or cirrhosis.

\section{Discussion}

The development of tumours in the livers of patients $ᄋ$ treated with anabolic steroids has been recorded sporadically since 1965 (Recant and Lacy, 1965; Oㅡㅡㄹ Bernstein et al, 1971; Johnson et al, 1972; Guy and Auslander, 1973; Ziegenfuss and Carabasi, 1973; $\sigma$ Henderson et al, 1973; Meadows et al, 1974; N Farrell et al, 1975). Of the cases recorded to date the N non-tumorous portion of the liver was normal in 0 one, showed generalized peliosis hepatis in another, and postnecrotic cirrhosis in a third. In the remaining nine cases no comment was available on residual $\stackrel{\infty}{?}$ liver.

The liver in our case 1 showed generalized hyperplasia, hyperplastic hepatocytic nodules, and a $\stackrel{\mathbb{D}}{\circ}$ tumour which differed from these nodules not only $\overrightarrow{\mathbb{D}}$ by its gross size difference and macroscopic appear- $\frac{}{\sigma}$ ance but also by its microscopic architecture. The 


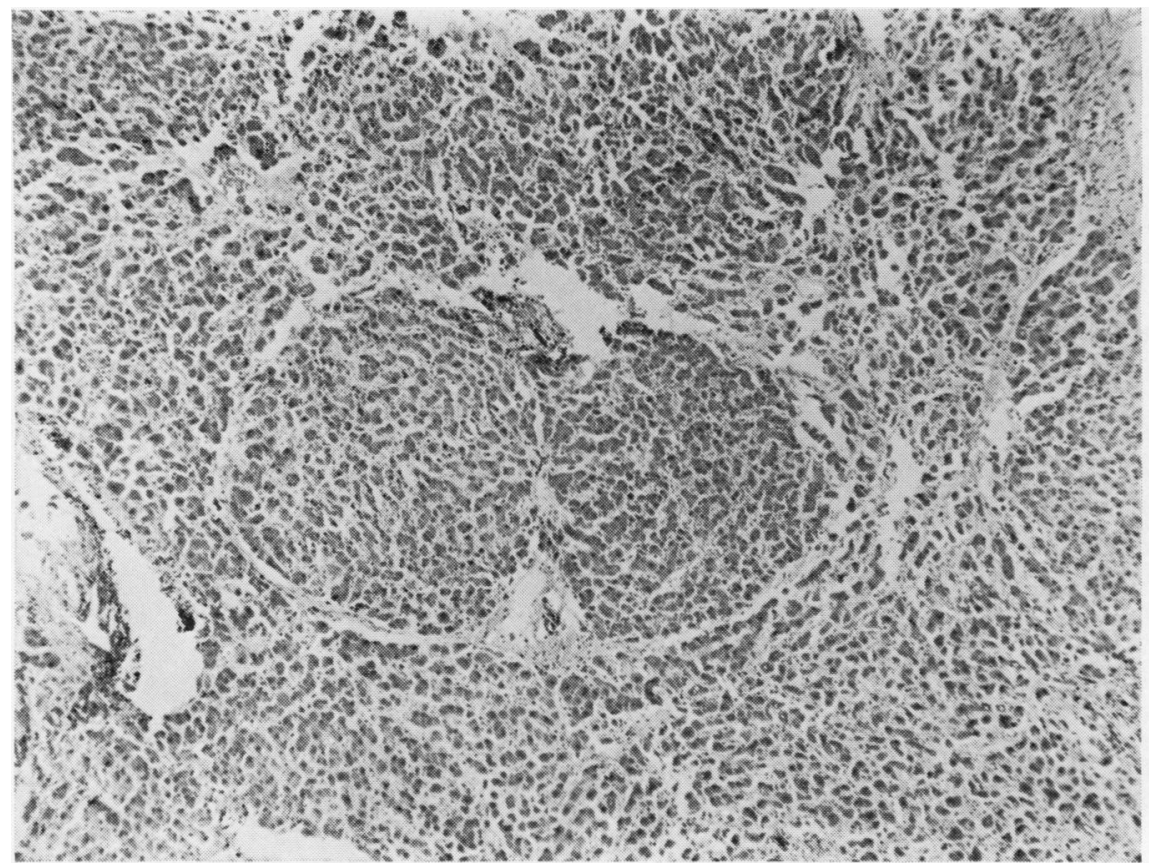

Fig 7 (a, b) Case 2. Hyperplastic hepatocyte nodules without surrounding fibrosis. Autolytic change in the adjacent parenchyma precludes evaluation of generalized hyperplasia. $H$ and $E \times 45$.

Fig 7a

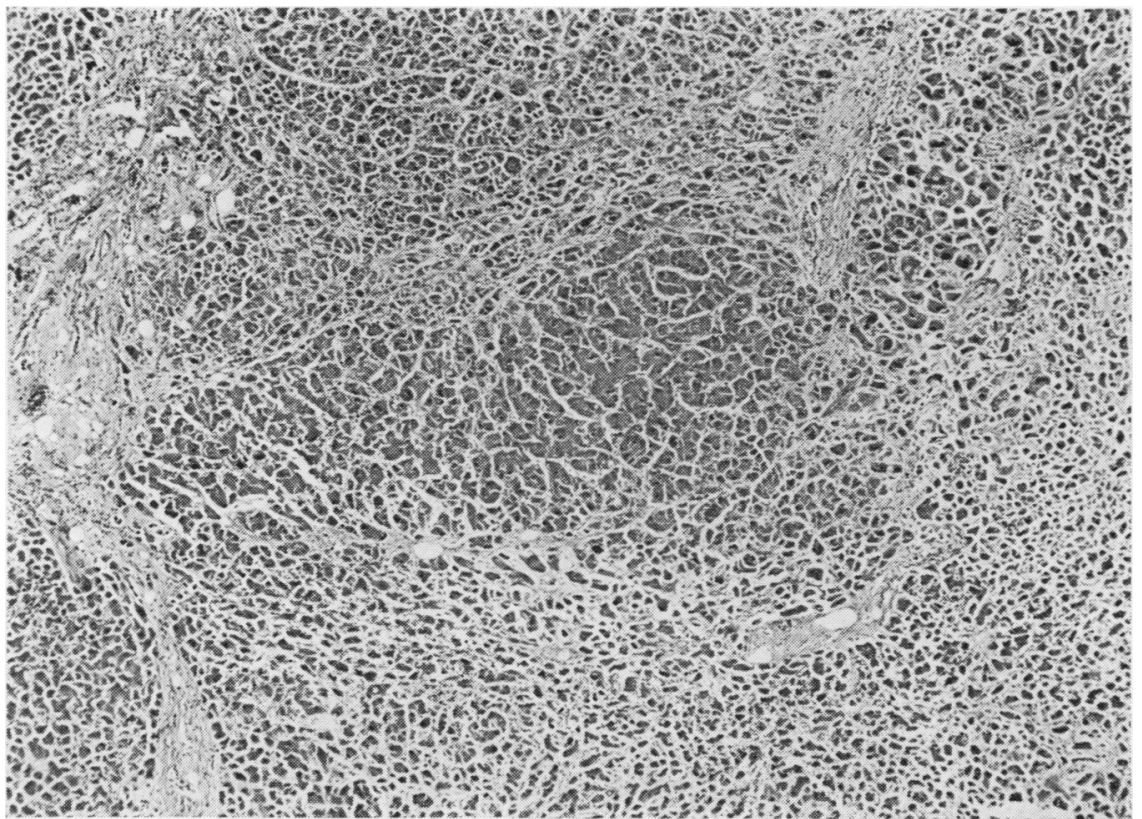




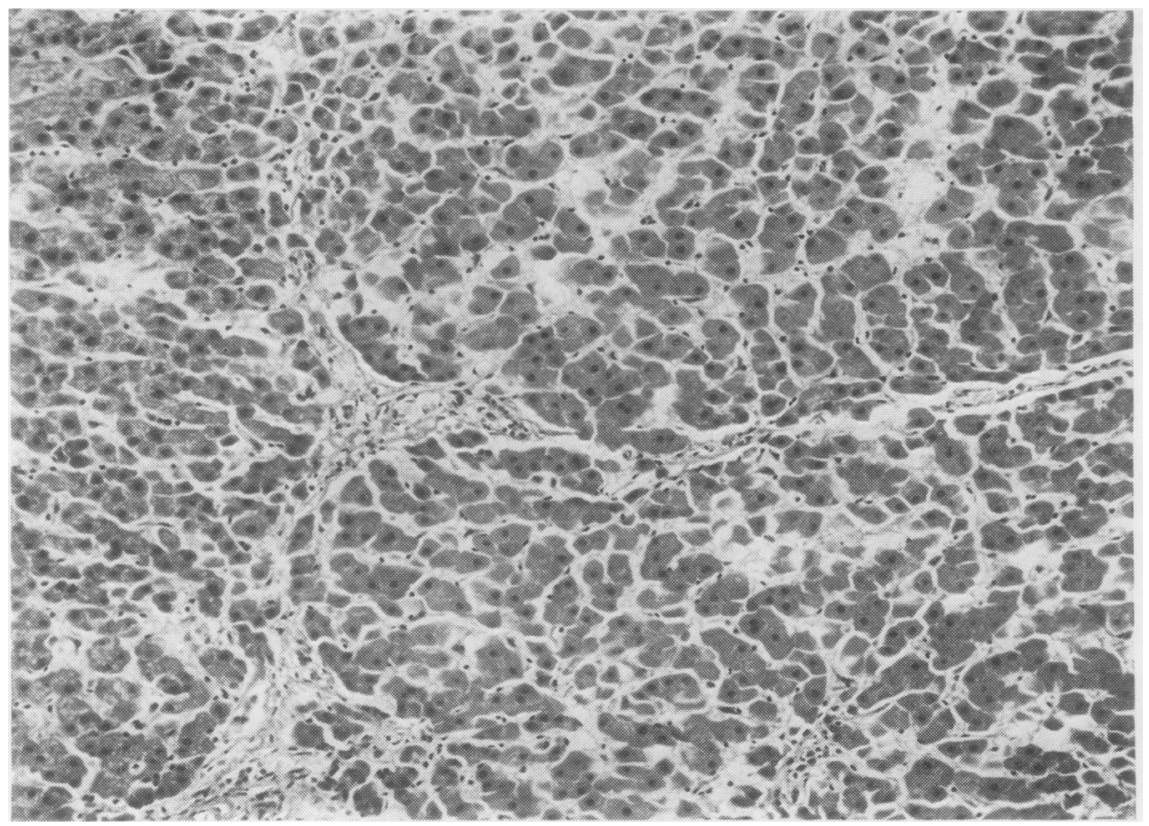

Fig 8 Case 3. Lowpower view of hyperplastic zone composed of enlarged hepatocytes arranged in thickened cell plates. $H$ and $E$ $\times 112$.
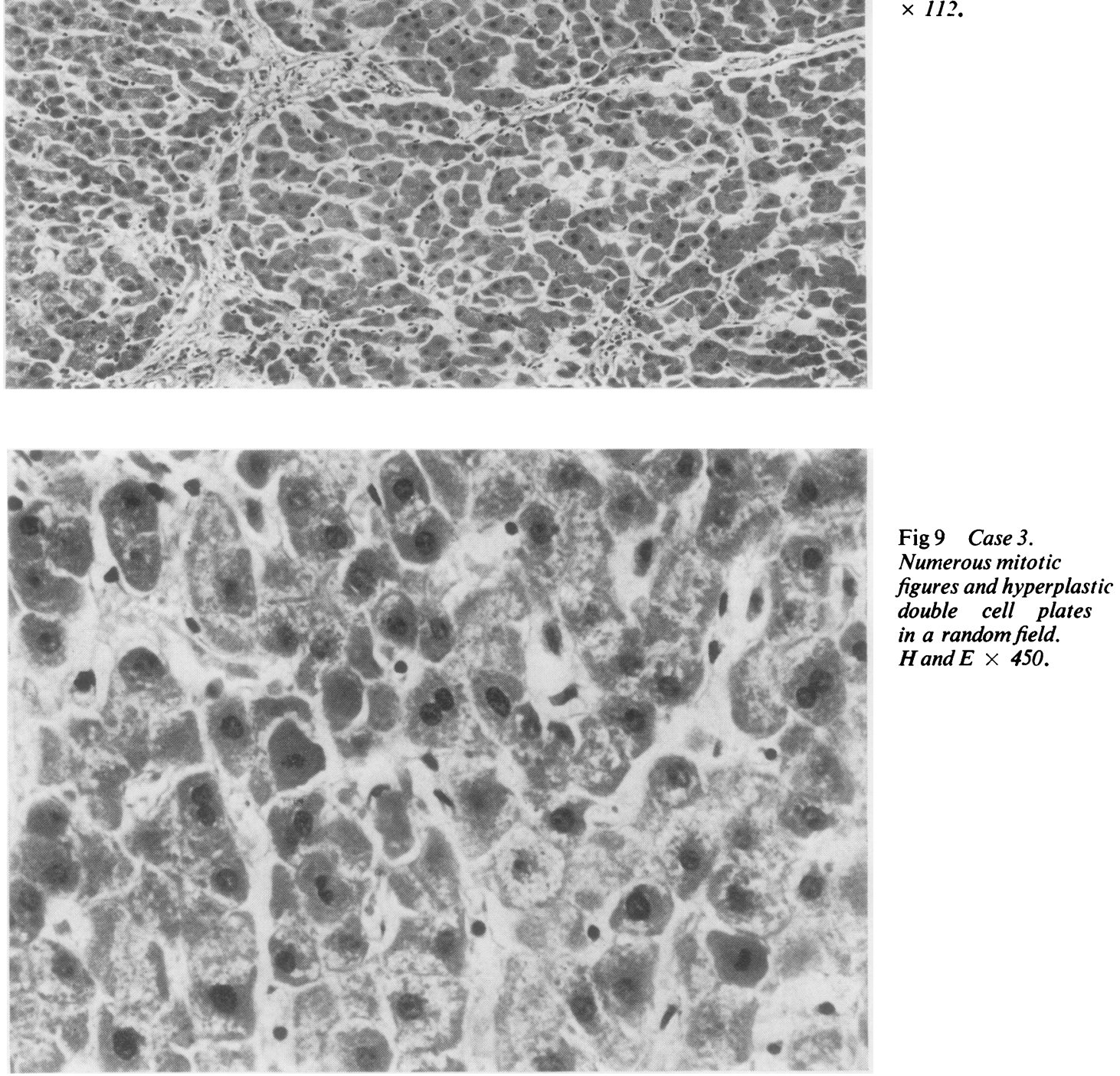

Fig 9 Case 3. Numerous mitotic figures and hyperplastic double cell plates in a random field. $H$ and $E \times 450$.

coexistence of the changes suggested the possibility that the liver tumour had evolved through the development of hyperplastic nodules. The question which then arose was whether the changes in the liver were associated with the anabolic steroid therapy or with the underlying Fanconi's anaemia.
Like most cases of Fanconi's anaemia this patient 7 had received prolonged therapy with anabolic ${ }^{\circ}$ steroids. In our other cases of aplastic anaemia the duration of treatment was only three months. Case $3 \vec{\otimes}$ received only $50 \mathrm{mg}$ per day but nevertheless the $\sigma$ liver showed generalized hyperplasia with thickened 
plates and increased mitoses. In case 2 the level of drug administration was more variable. Initially $100 \mathrm{mg}$ of oxymetholone daily was given; subsequently this was increased to $300 \mathrm{mg}$ but was stopped entirely during the terminal admission. In this patient scattered small hyperplastic nodules were found: autolysis made evaluation of the residual liver difficult but it was not thought to show generalized hyperplasia. These two cases support the view that hyperplasia and hyperplastic nodules may be associated with anabolic steroid therapy in the human. Although hyperplastic nodules in the liver are not necessarily associated with the development of hepatomas, for example in Felty's syndrome (Ranström, 1953; Blendis et al, 1974; Sweeney, 1975), the induction of liver tumours in animals by a variety of chemical carcinogens progresses through the formation of hyperplastic nodules (Farber, 1974) and may be influenced by the administration of androgens (Lingeman, 1974), forming a parallel with our findings in the human cases.

It has previously been suggested that the development of the liver tumours in Fanconi's anaemia is associated with the genetic abnormality rather than with the therapy. It is difficult to estimate the risk of development of tumours in Fanconi's anaemia because of the small number of cases available. Swift (1971), in a statistical study of heterozygous relatives, estimated that the gene increased the risk of malignancy as compared to that in the general population two to five times. In patients with the disease leukaemia has been reported eight times (Dosik et al, 1970) and six squamous carcinomas have been recorded in four patients (Swift et al, 1971), although only one of these metastasized. However, of the patients with Fanconi's anaemia who developed hepatic tumours all but one had received anabolic steroids. This single exception (Cattan et al, 1974) may well differ from the other patients since associated cirrhosis and extrahepatic metastases were present. Liver tumours have, moreover, been reported in patients receiving anabolic adrogenic steroids for other reasons (Lancet, 1973; Ziegenfuss and Carabasi, 1973; Farrell et al, 1975).

Although the tumours occurring in patients receiving oral contraceptives are usually of the type known as 'focal nodular hyperplasia' (Mays et al, 1974), they differ from the purely hepatocytic nodules seen in our cases 1 and 2 in having a biliary component, and although they may be multiple (Stauffer et al, 1975) they have not been shown to be associated with microscopic nodules.

It appears probable that androgen therapy causes hyperplasia, nodules, and tumours in the human liver but it is not clear to what extent this is a dose- dependent phenomenon. Most of the reported cases have had sustained high-dose therapy but it seems likely that a substantial number of athletes and patients receiving 'replacement therapy' may be exposed to an unnecessary hazard.

We wish to thank Dr E. Gordon Smith for permission to publish case 1, Professor H. K. Weinbren for helpful discussion, W. Hinkes for photographic work, and Mrs I. Fisher for secretarial assistance.

\section{References}

Bernstein, M. S., Hunter, R. L., and Yachnin, S. (1971). Hepatoma and peliosis hepatis developing in a patient with Fanconi's anemia. New Engl. J. Med., 284, 1135-1136.

Blendis, L. M., Parkinson, M. C., Shilkin, K. B., and Williams, R. (1974). Nodular regenerative hyperplasia of the liver in Felty's syndrome. Quart. J. Med,, 169, 25-32.

Cattan, D., Vesin, P., Wautier, J., Kalifat, R., and Meignan, S. (1974). Liver tumours and steroid hormones. (Letter.) Lancet, $1,878$.

Dosik, H., Hsu, L. Y., Todaro, G. J., Lee, S. L., Hirschhorn, K., Selirio, E. S., and Alter, A. A. (1970). Leukaemia in Fanconi's anaemia: cytogenetic and tumor virus susceptibility studies. Blood, 36, 341-352.

Farber, E. (1974). Pathogenesis of liver cancer. Arch. Path., 98, 145-148.

Farrell, G. C., Joshua, D. E., Uren, R. F., Baird, P. J., Perkins, K. W., and Kronenberg, H. (1975). Androgeninduced hepatoma. Lancet, 1, 430-431.

Guy, J. T. and Auslander, M. O. (1973). Androgenic steroids and hepatocellular carcinoma. (Letter.) Lancet, $1,148$.

Henderson, J. T., Richmond, J., and Sumerling, M. D. (1973). Androgenic-anabolic steroid therapy and hepatocellular carcinoma. (Letter.) Lancet, 1, 934.

Johnson, F. L., Feagler, J. R., Lerner, K. G., Majerus, P. W., Siegel, M., Hartmann, J. R., and Thomas, E. D. (1972) Association of androgenic-anabolic steroid therapy with development of hepatocellular carcinoma. Lancet, 2 , 1273-1276.

Lancet (1973). Editorial. Liver tumours and steroid hormones. 2, 1481.

Lingeman, C. H. (1974). Liver-cell neoplasms and oral contraceptives. (Letter.) Lancet, 1, 64.

Mays, E. T., Christopherson, W. M., and Barrows, G. H. (1974). Focal nodular hyperplasia of the liver. Possible relationship to oral contraceptives. Amer. J. clin. Path., 61, 735-746.

Meadows, A. T., Naiman, J. L., and Valdes-Dapena, M. (1974). Hepatoma associated with androgen therapy for aplastic anemia. J. Pediat., 84, 109-110.

Ranström, S. (1953). Miliary hepatocellular adenomatosis. Acta path. microbiol. scand., 33, 225-229.

Recant, L. and Lacy, P. (1965). Fanconi's anemia and hepatic cirrhosis. Amer. J. Med., 39, 464-475.

Stauffer, J. Q., Lapinski, M. W., Honold, D. J., and Myers, J. K. (1975). Focal nodular hyperplasia of the liver and intrahepatic haemorrhage in young women on oral contraceptives. Ann. intern. Med., 83, 301-306.

Sweeney, E. C. (1975). Non-cirrhotic portal hypertension in Felty's syndrome. Irish J. med. Sci., 144, 172-174.

Swift, M. (1971). Fanconi's anaemia in the genetics of neoplasia. Nature (Lond.), 230, 370-373.

Swift, M., Zimmerman, D., and McDonough, E. R. (1971). Squamous cell carcinomas in Fanconi's anemia. J. Amer. med. Ass., 216, 325-326.

Ziegenfuss, J. and Carabasi, R. (1973). Androgens and hepatocellular carcinoma. (Letter.) Lancet, 1, 262. 